\title{
Cinética da degradação de geleiada de morango
}

\author{
Kinetics of strawberry jelly degradation
}

\author{
Ana Carolina Almeida MIGUEL ${ }^{1 \star}$, Silvana ALBERTINI ${ }^{1}$, Marta Helena Fillet SPOTO ${ }^{1}$
}

\begin{abstract}
Strawberry jelly was stored at 20 (control), 30 (room) and 40 (accelerated) ${ }^{\circ} \mathrm{C}$ in order to evaluate their shelf lives. The shelf-life evaluation was based on objective color readings of L a b Hunter color (Minolta Chroma Meter CR-400) and on subjective color methods, smell, flavor, and texture (Quantitative Descriptive Analysis) measurements. Objective and subjective analyses were carried out for 180 days at 30 -day intervals under three different conditions. Experimental data show that the color degradation followed the model of a first order kinetic reaction. The Arrhenius model was applied to the reaction rates $(\mathrm{k})$ at each temperature obtaining activation energy $\left(\mathrm{E}_{\mathrm{a}}\right)$ of $5.66 \mathrm{kcal} \mathrm{mol}{ }^{-1}$ and $\mathrm{Q}_{10}$ of 1.36 . The jellies showed adequate quality with relation to acid ascorbic content in the occasion of the processing, but they had presented low vitamin $\mathrm{C}$ retention. On the $60^{\text {th }}$ day, the vitamin C content reduced more than $98 \%$, regardless of the storage condition. The jellies stored at $40{ }^{\circ} \mathrm{C}$ proved more sensitive to the alterations in the color, and such temperature affected negatively the sensory attributes indicated by the browning and losses of smell, flavor, and texture. The results suggest that strawberry jellies must be stored under controlled conditions of temperature $\left(20\right.$ to $\left.30^{\circ} \mathrm{C}\right)$.
\end{abstract}

Keywords: color degradation kinetics; strawberry jelly; shelf-life.

\section{Resumo}

Geleiadas de morango foram armazenadas à temperatura de $20^{\circ} \mathrm{C}$ (controle), $30^{\circ} \mathrm{C}$ (ambiente) e $40{ }^{\circ} \mathrm{C}$ (acelerada), a fim de se avaliar a vidade-prateleira. A avaliação da vida-de-prateleira foi baseada em leituras objetivas de cor L, a e b Hunter (Minolta Chroma Meter CR-400b) e subjetivas de cor, odor, sabor e textura (Análise Descritiva Quantitativa). As análises objetivas e subjetivas foram realizadas a cada 30 dias, por seis meses, nas três condições de armazenamento. Os dados obtidos mostraram que a reação cinética de degradação da cor se ajusta ao modelo cinético de $1^{\mathrm{a}}$ ordem. O modelo de Arrhenius foi aplicado às velocidades de reação (k), nas diferentes temperaturas, fornecendo uma energia de ativação $\left(\mathrm{E}_{\mathrm{a}}\right.$ ) de 5,66 kcal.mol-1 e um valor de $\mathrm{Q}_{10}$ de 1,36. As geleiadas apresentaram qualidade adequada com relação ao teor de ácido ascórbico na ocasião do processamento, porém apresentaram baixa taxa de retenção de vitamina $\mathrm{C}$, tendo, aos 60 dias, seu conteúdo reduzido em mais de $98 \%$, independente da condição de armazenamento. As geleiadas mantidas a $40{ }^{\circ} \mathrm{C}$ mostram-se mais sensíveis às alterações na cor, e esta temperatura afetou negativamente os atributos sensoriais, indicados pelo escurecimento e perdas de odor, sabor e textura. Estes resultados sugerem que as geleiadas devem ser armazenadas sob condições controladas de temperatura $\left(20-30{ }^{\circ} \mathrm{C}\right)$.

Palavras-chave: cinética de degradação de cor; geleiada de morango; vida-de-prateleira.

\section{Introdução}

O morango é um fruto que apresenta estrutura frágil e alta taxa de atividade respiratória, resultando em uma conservação pós-colheita relativamente curta. Em razão da produção concentrada nos meses de setembro a dezembro e da rápida perda de qualidade pós-colheita, há uma grande limitação quanto ao fornecimento dos frutos ao mercado in natura. Uma alternativa viável para o aproveitamento econômico desses frutos é a industrialização na forma de geléias e geleiadas (VENDRUSCOLO; VENDRUSCOLO, 2007).

A conservação do morango por longos períodos, com propriedades semelhantes às da fruta fresca ainda é um desafio tecnológico a ser vencido. Também por sua composição química complexa, todos os produtos processados de morango, geleiada, por exemplo, mesmo elaborada e embalada com alta tecnologia, têm vida-de-prateleira relativamente curta, com perdas expressivas de cor e sabor. A perda de quali- dade é diretamente proporcional ao tempo e à temperatura elevados aos quais o produto é exposto no processamento e durante seu período de comercialização (VENDRUSCOLO; VENDRUSCOLO, 2007).

O comportamento de geléias durante o armazenamento tem sido estudado, e observou-se que geléias de morango escurecem facilmente durante o armazenamento devido ao elevado teor de antocianina, sensível à degradação (FREEDMAN; FRANCIS, 1984). As condições de processo e o tempo de estocagem também influenciam a deterioração da cor dos produtos contendo antocianina (SKREDE et al., 1992).

A aceitação ou rejeição pelo consumidor é dependente da garantia de retenção de cor, sabor, qualidade do aroma e conteúdo de nutrientes. Este trabalho visou avaliar o efeito da temperatura de armazenamento sobre a vida-de-prateleira de geleiada de morango.

Recebido para publicação em 10/8/2007

Aceito para publicação em 14/1/2008 (002736)

${ }^{1}$ Departamento de Agroindústria, Alimentos e Nutrição, Escola Superior de Agricultura "Luiz de Queiroz”, Av. Pádua Dias, 11, CP 9, CEP 13418-900, Piracicaba- SP, Brasil, E-mail: acmiguel@esalq.usp.br

${ }^{*}$ A quem a correspondência deve ser enviada 


\section{Material e métodos}

\subsection{Materiais}

Para elaboração das geleiadas, foram utilizados morangos da variedade Oso Grande adquiridos no comércio de Piracicaba (SP), sacarose, pectina (com $115^{\circ} \mathrm{SAG}$ ).

\subsection{Métodos}

Processo de elaboração das geleiadas

A elaboração das geleiadas de morango foi realizada na Planta Piloto de Processamento do Departamento de Agroindústria, Alimentos e Nutrição da ESALQ/USP, localizada em Piracicaba (SP), em outubro de 2006.

Os frutos foram inicialmente selecionados, ou seja, descartaram-se aqueles que estavam machucados ou deteriorados e os verdes. Em seguida, procedeu-se à lavagem dos morangos visando eliminar as sujicidades mais grosseiras, à retirada do pedicelo e das sépalas, à imersão dos frutos em solução de dicloroisocianurato de sódio dihidratado (200 ppm) por 15 minutos e à drenagem deles por 3 minutos. Os morangos foram cortados em pedaços e fervidos à pressão atmosférica em tacho aberto, até obtenção do suco e, posteriormente, filtrado com o auxílio de peneiras de 35 mesh.

Aos morangos cortados, foram adicionados sacarose $(0,75: 1 \mathrm{p} / \mathrm{p}$ em relação à massa total dos frutos) e pectina (quantidade calculada com base no ${ }^{\circ} \mathrm{SAG}$ e peso de sacarose).

A formulação foi preparada com concentração final de sólidos solúveis de $68^{\circ}$ Brix. Os produtos foram acondicionados a quente $\left(85^{\circ} \mathrm{C}\right)$, em embalagens de vidro, previamente esterilizadas a $100^{\circ} \mathrm{C} / 30$ minutos, com capacidade para $250 \mathrm{~g}$ e fechadas com tampa de metal. $\mathrm{O}$ tratamento térmico foi efetuado em banho-maria a $100{ }^{\circ} \mathrm{C}$ por 15 minutos e, em seguida, os frascos foram invertidos para promover a esterilização das tampas por 15 minutos, resfriados à temperatura ambiente e lacrados. Para acompanhamento da vida-de-prateleira, as geleiadas foram armazenadas em câmaras de estocagem nas temperaturas de $20{ }^{\circ} \mathrm{C}$ (temperatura controle), $30^{\circ} \mathrm{C}$ (temperatura ambiente) e $40^{\circ} \mathrm{C}$ (temperatura acelerada) por 180 dias.

\section{Caracterização das amostras}

Para a caracterização das amostras de geleiadas, foram realizadas as seguintes análises:

\section{a) $\mathrm{pH}$}

Leitura direta em potenciômetro previamente calibrado com soluções-padrão 4,0 e 7,0. Análise realizada em triplicata (INSTITUTO ADOLFO LUTZ, 1985b).

\section{b) Sólidos solúveis}

Foram determinados, em triplicata, por leitura direta em refratômetro calibrado à temperatura utilizada de $20{ }^{\circ} \mathrm{C}$ (LABORATORY TECHNIQUES IN FOOD ANALYSIS, 1973). c) Teor de ácido ascórbico

Foi determinado por titulometria com solução de 2,6 dicloro-fenol-indofenol de sódio em alíquota de geleiada diluída em ácido oxálico a $0,5 \%$, de acordo com Strohecker e Henning (1967).

\section{d) Umidade}

Determinada em balança determinadora de umidade Tecnal modelo B-Top-Ray, por radiação infravermelha, a qual permitiu expressar os resultados em porcentagem (\%).

\section{e) Cinzas (\%)}

Determinadas através da incineração das amostras de geleiada (triplicata) em mufla à temperatura de $500-600{ }^{\circ} \mathrm{C}$ por 4 horas (AOAC, 1992).

\section{f) Proteínas (\%)}

O teor de nitrogênio total foi determinado pelo método de Kjeldahl, sendo o teor proteico determinado pela multiplicação do conteúdo de nitrogênio total pelo fator de 6,25 (AOAC, 1992).

\section{g) Lipídios (\%)}

O teor de lipídios foi determinado, em triplicata, utilizandose o extrator de Sohxlet. Na extração, foi utilizado como solvente o hexano em refluxo contínuo da amostra durante 8 horas. Recuperado o hexano, os balões foram colocados em estufa a $70{ }^{\circ} \mathrm{C}$ até total evaporação do solvente, mantidos por 1 hora a $105^{\circ} \mathrm{C}$, esfriados em dessecador e pesados. O teor de lipídios foi determinado pela diferença de peso entre o balão com óleo e o balão vazio (AOAC, 1992).

\section{Acompanhamento da vida-de-prateleira das amostras}

Para acompanhamento da vida-de-prateleira das amostras de geleiada de morango, foram realizadas as seguintes análises:

\section{pH, sólidos solúveis, teor de ácido ascórbico e umidade}

Mesma metodologia descrita anteriormente. O objetivo foi avaliar alguma alteração ao longo do tempo nestes parâmetros.

\section{Cor objetiva}

Determinada diretamente no colorímetro Minolta Chroma Meter CR-400b, sistema Hunter Lab, previamente calibrado. O sistema Lab Hunter é um sistema de coordenadas retangulares que define a cor em termos de luminosidade (L), vermelho versus verde (a); e amarelo versus azul (b). Foi calculada a diferença total de cor $(\Delta \mathrm{E})$ de acordo com a Equação 1:

$\Delta \mathrm{E}=\left[(\Delta \mathrm{L})^{2}+(\Delta \mathrm{a})^{2}+(\Delta \mathrm{b})^{2}\right]^{1 / 2}$

onde $\Delta$ é a diferença entre cada parâmetro de cor da amostra inicial (tempo zero) e da amostra armazenada.

As análises foram realizadas, em triplicata, a cada 30 dias para as temperaturas de $20^{\circ} \mathrm{C}$ (controle), 30 e $40^{\circ} \mathrm{C}$. 
Os dados obtidos da alteração total da cor das amostras foram analisados quanto à ordem da reação de degradação e calculadas a velocidade de reação $(k)$ e a energia de ativação $\left(\mathrm{E}_{\mathrm{a}}\right)$ nas respectivas temperaturas, além do quociente entre as velocidades de reação a uma determinada temperatura e a uma temperatura $10{ }^{\circ} \mathrm{C}$ mais alta $\left(\mathrm{Q}_{10}\right)$ (TEIXEIRA NETO; VITALI, 2004).

Para a determinação da ordem de reação e sua constante de velocidade, foram plotados os valores de diferença total de cor $(\Delta \mathrm{E})$ versus tempo de armazenamento para cada temperatura, e realizada a regressão linear, de cada temperatura, correspondente aos valores de $\mathrm{k}$ (velocidade de reação).

Para a dependência da velocidade da reação com a temperatura, foi utilizado o Modelo de Arrhenius.

A inclinação do gráfico $\ln (\mathrm{k})$ versus $1 / \mathrm{T}\left(\mathrm{k}^{-1}\right)$ é conhecida como $\mathrm{E}_{\mathrm{a}} / \mathrm{R}$. Sendo $\mathrm{R}=1,987 \mathrm{cal} / \mathrm{gmol}$.k, determina-se a energia de ativação $\left(\mathrm{E}_{\mathrm{a}}\right)$.

Para a determinação de $\mathrm{Q}_{10}$, foi utilizada a seguinte Equação 2:

$\mathrm{Q}_{10}=10^{\mathrm{E} 20.04 . \mathrm{T} 2}$

onde T (kelvin) é a temperatura média na qual foi determinada a energia de ativação.

\section{Cor subjetiva, odor, sabor e textura}

Para avaliar o comportamento da geleiada de morango, foram realizadas periodicamente análises sensoriais descritivas quantitativas (ADQ), nas quais se avaliaram os atributos de aparência, odor, sabor e textura, por uma equipe de 8 julgadores treinados (ABNT, 1993).

Para a seleção e o treinamento da equipe, foram realizados os testes dos gostos básicos (ácido, doce, amargo e salgado), teste triangular, levantamento de atributos, elaboração da ficha, definição de materiais de referência, teste sensorial com materiais de referência e análise sensorial (SKREDE, 1992). A etapa de treinamento constou de 16 sessões, as quais foram realizadas no período de 2 meses, em cabines individualizadas, conforme indicação da International Organization for Standardization (1988).

O julgamento das amostras foi realizado pelo teste de avaliação de atributos, a partir de uma escala de intervalo não estruturada de $9 \mathrm{~cm}$, conforme as indicações da International Organization for Standardization (1987). Os 7 atributos avaliados foram cor vermelha, sendo que o valor zero representou "pouco vermelho" e o nove representou "muito vermelho"; brilho, tendo como valor zero o termo "pouco brilho" e o nove "muito brilho"; odor característico, sendo que o valor zero representou "odor pouco característico" e o nove representou "odor muito característico"; sabor característico, tendo como valor zero o termo "sabor pouco característico" e o nove o termo "sabor muito característico"; e consistência do gel, sendo que o valor zero caracterizou "gel mole" e o nove, "gel duro".

As amostras, mantidas nas três condições de armazenamento $\left(20,30 \mathrm{e} 40^{\circ} \mathrm{C}\right)$, foram apresentadas aos julgadores em copos plásticos descartáveis revestidos com filme plástico, codificados com três algarismos aleatórios. Cada amostra foi constituída por cerca de $20 \mathrm{~g}$ de geleiada, à temperatura ambiente, de acordo com as recomendações da International Organization for Standardization (1982).

Os resultados obtidos foram avaliados estatisticamente através de análise de variância pelo teste $F$, comparação das médias pelo Teste de Tukey, ao nível de 5\% de probabilidade, de acordo com Gomes (1982).

\section{Resultados e discussão}

\subsection{Resultados da caracterização das amostras}

A caracterização das amostras de geleiada de morango encontra-se na Tabela 1.

Em todos os parâmetros, não ocorreram variações marcantes entre as geleiadas no dia 0 , o que já era esperado, pois o uso de diferentes temperaturas não poderia interferir, em um curto espaço de tempo, no conteúdo destes componentes.

Em todas as amostras, foi detectada a presença de ácido ascórbico, indicando que a polpa de morango foi submetida a um processamento adequado durante a elaboração das geleiadas (Tabela 1). A oxidação do ácido ascórbico pode ocorrer por via aeróbica principalmente nos processos de extração e tratamento térmico (MOURA et al., 2001).

O elevado teor de sólidos solúveis das geleiadas aliado à baixa umidade e $\mathrm{pH}(<4,5)$ dificulta a deterioração microbiológica do produto (Tabela 1 ).

\subsection{Resultados do acompanhamento da vida-de-prateleira das amostras}

pH, sólidos solúveis, ácido ascórbico e umidade

Houve pequena variação no $\mathrm{pH}$ das amostras de geleiada, porém não significativa. A geleiada mantida a $20^{\circ} \mathrm{C}$ passou de $\mathrm{pH}=3,34$ para $\mathrm{pH}=3,48$ aos 60 dias, mantendo-se estável até 180 dias, enquanto que as amostras conservadas a 30 e a $40^{\circ} \mathrm{C}$ apresentaram manutenção dos valores de $\mathrm{pH}$ ao longo do período de armazenamento, permanecendo ao redor de 3,36 e de 3,38 , respectivamente.

Com relação ao teor de sólidos solúveis ( ${ }^{\circ}$ Brix), não houve alteração com o avanço dos dias e a variação entre as amostras mantidas nas três condições de armazenamento foi praticamente nula.

Tabela 1. Caracterização inicial das geleiadas de morango.

\begin{tabular}{lrrr}
\hline \multicolumn{1}{c}{ Análises } & \multicolumn{1}{c}{$20^{\circ} \mathrm{C}$} & \multicolumn{1}{c}{$30^{\circ} \mathrm{C}$} & \multicolumn{1}{c}{$40^{\circ} \mathrm{C}$} \\
\hline $\mathrm{pH}$ & $3,34 \pm 0,00$ & $3,36 \pm 0,00$ & $3,38 \pm 0,00$ \\
Sólidos solúveis ( $\left.{ }^{\circ} \mathrm{Brix}\right)$ & $69,0 \pm 0,00$ & $69,3 \pm 0,00$ & $68,9 \pm 0,00$ \\
Ácido ascórbico (mg.100 g $\left.{ }^{-1}\right)$ & $187,5 \pm 0,00$ & $187,5 \pm 0,00$ & $187,5 \pm 0,00$ \\
Umidade (\%) & $27,32 \pm 0,00$ & $28,22 \pm 0,00$ & $26,86 \pm 0,00$ \\
Cinzas (\%) & $0,19 \pm 0,02$ & $0,16 \pm 0,02$ & $0,15 \pm 0,04$ \\
Proteína (\%) & $0,93 \pm 0,13$ & $0,96 \pm 0,11$ & $0,90 \pm 0,12$ \\
Gordura (\%) & $0,64 \pm 0,05$ & $0,64 \pm 0,08$ & $0,60 \pm 0,04$ \\
\hline
\end{tabular}


De acordo com a Tabela 2, observou-se que, em todas as amostras, independente da temperatura de armazenamento, houve diminuição do teor de ácido ascórbico em mais de 98\% do teor inicial (187,5 mg ácido ascórbico.100 g $\mathrm{g}^{-1}$ ) após 180 dias de estocagem (Tabela 2), estando em conformidade com a constatação de Gava (1984), que verificou que o ácido ascórbico é perdido em função do tempo. Skrede et al. (1992) constataram, em estudo realizado com xarope de morango, que as amostras tiveram seu conteúdo de ácido ascórbico diminuído em menos de 50\% em 6 meses de armazenamento.

As amostras de geleiada armazenadas a 30 e a $40{ }^{\circ} \mathrm{C}$ apresentaram significativa diminuição do teor de umidade após 60 dias de armazenamento, enquanto que as mantidas a $20^{\circ} \mathrm{C}$ mostraram redução expressiva após 90 dias (Tabela 3). Analisando-se o efeito das temperaturas, verificou-se que a partir dos 30 dias, as amostras mantidas a $40^{\circ} \mathrm{C}$ foram as que apresentaram menor teor de umidade, o que pode ser atribuído ao efeito da alta temperatura sobre a água livre na geleiada, implicando na formação de gel mais consistente.

\section{Cor objetiva}

As geleiadas de morango, independente da temperatura de armazenamento, tiveram alterações no parâmetro de cor ao longo do tempo, tornando-se mais escuras (diminuição de $\mathrm{L}$ ). Entretanto, as amostras armazenadas a $20{ }^{\circ} \mathrm{C}$ mostraram-se mais vermelhas (aumento de a) e mais amarelas (aumento de b), enquanto que as mantidas a 30 e $40^{\circ} \mathrm{C}$ se tornaram menos vermelhas (diminuição de a) e mais amarelas (aumento de b).

Produtos contendo antocianinas como é o caso da geleiada de morango durante o processamento e estocagem são susceptíveis à deterioração na cor resultante de efeitos combinados da degradação da antocianina e da formação de pigmentos escuros (SKREDE et al., 1992). As alterações na cor durante a estocagem foram diretamente proporcionais ao aumento da temperatura de armazenamento, ou seja, ocorreram de maneira mais pronunciada na geleiada mantida a $40{ }^{\circ} \mathrm{C}$. Observou-se,

Tabela 2. Valores médios do teor de ácido ascórbico em geleiadas de morango, em função da temperatura e do tempo de armazenamento.

\begin{tabular}{cccccc}
\hline $\begin{array}{c}\text { Temperatura } \\
\left({ }^{\circ} C\right)\end{array}$ & 1 dia & 30 dias & 60 dias & 90 dias & 180 dias \\
\hline 20 & $187,50^{\mathrm{aA}}$ & $185,20^{\mathrm{aA}}$ & $5,77^{\mathrm{bA}}$ & $4,24^{\mathrm{bA}}$ & $1,65^{\mathrm{cA}}$ \\
30 & $187,50^{\mathrm{aA}}$ & $180,20^{\mathrm{aA}}$ & $5,77^{\mathrm{bA}}$ & $4,37^{\mathrm{bA}}$ & $1,90^{\mathrm{cA}}$ \\
40 & $187,50^{\mathrm{aA}}$ & $166,70^{\mathrm{bB}}$ & $0,61^{\mathrm{cB}}$ & $0,37^{\mathrm{cB}}$ & $0,28^{\mathrm{cA}}$ \\
\hline
\end{tabular}

Médias seguidas de pelo menos uma letra comum, minúscula nas linhas e maiúscula nas colunas, não diferem significativamente entre si, pelo teste de Tukey $(\mathrm{p}<0,05)$. também, que ocorreu um incremento nos valores de $\Delta \mathrm{E}$ (diferença total da cor) proporcional ao aumento da temperatura e do tempo de estocagem, representando perdas significativas da cor da amostra original. As alterações de cor foram bastante acentuadas nos 90 dias de armazenamento e apresentaram leve incremento até o final da estocagem.

Com base nos dados obtidos, determinou-se a ordem da reação da diferença total de cor (Figura 1) para as geleiadas de morango mantidas nas três temperaturas de armazenamento. As reações se ajustam ao modelo cinético de $1^{\text {a }}$ ordem para todas as amostras. Resultados semelhantes foram encontrados por Lozano e Ibarz (1997) na quantificação das perdas de cor durante o processamento de polpas de frutas armazenadas a diferentes temperaturas. Skrede et al. (1992) também constataram que a velocidade de degradação da antocianina em xarope de morango se ajusta ao modelo cinético de $1^{\text {a }}$ ordem.

A Tabela 4 mostra os parâmetros cinéticos da diferença total de cor $(\Delta \mathrm{E})$ para as geleiadas de morango. Os valores da energia de ativação $\left(\mathrm{E}_{\mathrm{a}}\right)$ foram calculados para a diferença total de cor, tendo seguido o modelo de Arrhenius. Para a geleiada de morango, a energia de ativação necessária para alteração da cor é $\mathrm{E}_{\mathrm{a}}=5,66 \mathrm{kcal} \cdot \mathrm{mol}^{-1}$.

Quanto ao valor de $\mathrm{Q}_{10}$, verificou-se que, a cada aumento de $10^{\circ} \mathrm{C}$ de temperatura, a vida-de-prateleira é multiplicada por 1,36, mostrando expressiva alteração na cor com a temperatura; requerendo armazenamento à baixa temperatura, se possível.

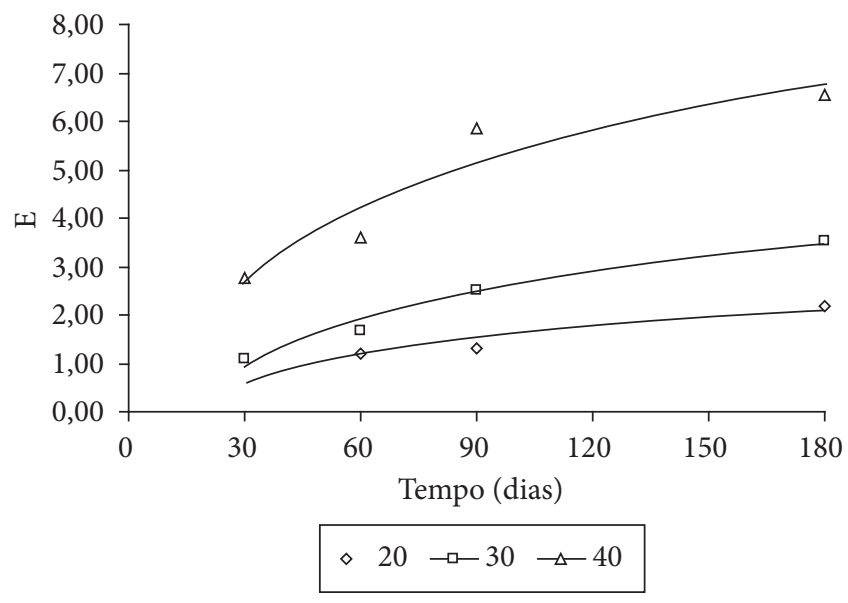

Figura 1. Modelo cinético da mudança de cor da geleiada de morango, com relação à diferença total de cor $(\Delta \mathrm{E})$.

Tabela 3. Valores médios do teor de umidade em geleiadas de morango, em função da temperatura e do tempo de armazenamento.

\begin{tabular}{cccccl}
\hline Temperatura $\left({ }^{\circ} \mathrm{C}\right)$ & 1 dia & 30 dias & 60 dias & 90 dias & 180 dias \\
\hline 20 & $27,32^{\mathrm{aA}}$ & $26,47^{\mathrm{abAB}}$ & $26,00^{\mathrm{abA}}$ & $25,85^{\mathrm{bA}}$ & $25,51^{\mathrm{bA}}$ \\
30 & $28,22^{\mathrm{aA}}$ & $27,87^{\mathrm{abA}}$ & $25,61^{\mathrm{bAB}}$ & $24,68^{\mathrm{bcAB}}$ & $23,34^{\mathrm{cB}}$ \\
40 & $26,86^{\mathrm{aA}}$ & $24,75^{\mathrm{abB}}$ & $22,64^{\mathrm{bB}}$ & $21,63^{\mathrm{bB}}$ & $15,22^{\mathrm{cC}}$ \\
\hline
\end{tabular}

Médias seguidas de pelo menos uma letra comum, minúscula nas linhas e maiúscula nas colunas, não diferem significativamente entre si, pelo teste de Tukey ( $\mathrm{p}<0,05)$. 
A oxidação do ácido ascórbico pode ocorrer também por via anaeróbica, levando à formação de hidroxi-metil-furfural e furfural, respectivamente, os quais, por sua vez, formam melanoidinas, que causam escurecimento, tal como na reação de Maillard. A fase anaeróbica ocorre durante o armazenamento e tende a ser mais intensa quanto mais alta for a temperatura.

Além do escurecimento não-enzímico (Maillard), ocorre também o aparecimento de sabor estranho nos produtos e consequente perda na qualidade e redução da vida-de-prateleira. Os valores de $\Delta \mathrm{E}$ foram crescentes para as três condições de armazenamento, sendo mais pronunciados nos produtos armazenados a $40{ }^{\circ} \mathrm{C}$, indicando que estas alterações ocorreram mais rapidamente.

\section{Cor subjetiva, odor, sabor e textura}

Conforme observado na Tabela 5, durante todo o período de avaliação, a cor subjetiva (cor vermelha) das amostras de geleiada de morango mantidas a 20 e $30^{\circ} \mathrm{C}$ não diferiram entre si, porém foram significativamente superiores às mantidas a $40^{\circ} \mathrm{C}$. A maior alteração de cor ocorreu nas amostras armazenadas a $40{ }^{\circ} \mathrm{C}$, caracterizando perda da coloração vermelha. O mesmo comportamento ocorreu na avaliação objetiva da cor, que evidenciou que estas alterações aconteceram mais rapidamente a temperaturas elevadas.

Tabela 4. Parâmetros cinéticos da diferença total de cor $(\Delta \mathrm{E})$ da geleiada de morango.

\begin{tabular}{lccc}
\hline Parâmetros cinéticos & \multicolumn{3}{c}{ Temperatura $\left({ }^{\circ} \mathrm{C}\right)$} \\
\cline { 2 - 4 } & 20 & 30 & 40 \\
\hline Ordem da reação & $1^{\mathrm{a}}$ & $1^{\mathrm{a}}$ & $1^{\mathrm{a}}$ \\
$\mathrm{K}\left(\mathrm{dia}^{-1}\right)$ & 0,000297 & 0,000343 & 0,000483 \\
$\mathrm{R}^{2}(\%)$ & 95,21 & 97,56 & 90,35 \\
$\mathrm{E}_{\mathrm{a}}\left(\mathrm{kcal} . \mathrm{mol}^{-1}\right)$ & - & 5,66 & - \\
$\mathrm{R}^{2}(\%)$ & - & 94,22 & - \\
$\mathrm{Q}_{10}$ & - & 1,36 & - \\
\hline
\end{tabular}

Em relação ao atributo sensorial odor característico, verificou-se que, em todas as amostras de geleiada, independente da temperatura de armazenamento, houve redução nos valores das notas com o avanço dos dias (Tabela 5). Entretanto, analisando-se o efeito da temperatura, observou-se que os provadores detectaram alterações mais pronunciadas no odor das geleiadas mantidas a $40^{\circ} \mathrm{C}$, sendo estas caracterizadas por odor tendendo ao pouco característico.

O sabor característico das amostras não diferiu significativamente entre si até os 60 dias de armazenamento, porém, a partir desse período, se observou que as geleiadas mantidas a $40{ }^{\circ} \mathrm{C}$ apresentaram perda de sabor de morango, sendo consideradas, conforme escala utilizada, semelhantes à geleiada fervida por 5 minutos (Tabela 5). Em relação ao efeito do período de conservação, verificou-se que as geleiadas armazenadas a $20 \mathrm{e}$ $30^{\circ} \mathrm{C}$ apresentaram redução significativa nos valores das notas aos 180 dias, enquanto que, para as amostras armazenadas a $40^{\circ} \mathrm{C}$, os provadores detectaram diminuição do sabor aos 90 dias. Entretanto, a redução nas notas das amostras conservadas a temperaturas mais baixas $\left(20\right.$ e $\left.30^{\circ} \mathrm{C}\right)$ não foi suficiente para descaracterizar o produto, não se podendo dizer o mesmo para as armazenadas a $40{ }^{\circ} \mathrm{C}$.

Em termos de consistência do gel, não foram observadas alterações nas amostras armazenadas a 20 e $30^{\circ} \mathrm{C}$, porém, nas amostras mantidas a $40^{\circ} \mathrm{C}$, os provadores detectaram perda da textura característica a partir do $90^{\circ} \mathrm{dia}$, a qual foi caracterizada por gel mole (Tabela 5).

De acordo com os resultados apresentados na Tabela 6, as temperaturas de armazenamento e o período de conservação não afetaram o atributo sensorial sabor doce, justificando os resultados obtidos na avaliação do teor de sólidos solúveis ( ${ }^{\circ}$ Brix).

$\mathrm{O}$ atributo brilho não variou significativamente entre as amostras, porém, durante o período de armazenamento, observou-se tendência à diminuição nos valores das notas. Entretanto, esta pequena redução, não foi suficiente para caracterizar as amostras como pouco brilhantes (Tabela 6).

Tabela 5. Valores médios para os atributos sensoriais de cor, sabor e textura das amostras de geleiada de morango.

\begin{tabular}{|c|c|c|c|c|c|c|}
\hline \multirow[t]{2}{*}{ Atributo } & \multirow[t]{2}{*}{ Temperatura $\left({ }^{\circ} \mathrm{C}\right)$} & \multicolumn{5}{|c|}{ Dias } \\
\hline & & 0 & 30 & 60 & 90 & 180 \\
\hline \multirow[t]{3}{*}{ Cor vermelha } & 20 & $9,33^{\mathrm{aA}}$ & $8,67^{\mathrm{aA}}$ & $9,43^{\mathrm{aA}}$ & $7,67^{\mathrm{bA}}$ & $10,00^{\mathrm{aA}}$ \\
\hline & 30 & $9,33^{\mathrm{aA}}$ & $9,00^{\mathrm{aA}}$ & $9,67^{\mathrm{aA}}$ & $8,67^{\mathrm{aA}}$ & $8,67^{\mathrm{aA}}$ \\
\hline & 40 & $9,33^{\mathrm{aA}}$ & $7,67^{\mathrm{bA}}$ & $2,00^{\mathrm{cB}}$ & $2,33^{\mathrm{cB}}$ & $1,00^{\mathrm{cB}}$ \\
\hline \multirow[t]{3}{*}{ Odor característico } & 20 & $9,33^{\mathrm{aA}}$ & $7,50^{\mathrm{bA}}$ & $8,33^{\mathrm{bAB}}$ & $7,67^{\mathrm{bA}}$ & $8,17^{\mathrm{bA}}$ \\
\hline & 30 & $9,33^{\mathrm{aA}}$ & $7,50^{\mathrm{cA}}$ & $8,67^{\mathrm{abA}}$ & $7,67^{\mathrm{cA}}$ & $8,00^{\text {bca }}$ \\
\hline & 40 & $9,33^{\mathrm{aA}}$ & $7,00^{\mathrm{bA}}$ & $7,33^{\mathrm{bB}}$ & $4,00^{\mathrm{dB}}$ & $5,50^{\mathrm{cB}}$ \\
\hline \multirow[t]{3}{*}{ Sabor característico } & 20 & $8,00^{\mathrm{bA}}$ & $8,00^{\mathrm{bA}}$ & $9,38^{\mathrm{aA}}$ & $8,78^{\mathrm{abA}}$ & $5,75^{\mathrm{cA}}$ \\
\hline & 30 & $8,00^{\mathrm{bA}}$ & $8,50^{\mathrm{bA}}$ & $9,63^{\mathrm{aA}}$ & $9,00^{\mathrm{abA}}$ & $5,75^{\mathrm{cA}}$ \\
\hline & 40 & $8,00^{\mathrm{aA}}$ & $8,00^{\mathrm{aA}}$ & $8,78^{\mathrm{aA}}$ & $4,50^{\mathrm{bB}}$ & $2,50^{\mathrm{cB}}$ \\
\hline \multirow[t]{3}{*}{ Consistência do gel } & 20 & $4,75^{\mathrm{bA}}$ & $6,00^{\mathrm{abA}}$ & $6,00^{\mathrm{abA}}$ & $6,75^{\mathrm{aA}}$ & $5,50^{\mathrm{abA}}$ \\
\hline & 30 & $5,00^{\mathrm{bA}}$ & $5,75^{\mathrm{abA}}$ & $5,75^{\mathrm{abA}}$ & $6,75^{\mathrm{aA}}$ & $5,00^{\mathrm{bA}}$ \\
\hline & 40 & $4,75^{\mathrm{abA}}$ & $5,00^{\mathrm{aA}}$ & $5,00^{\mathrm{aA}}$ & $3,50^{\mathrm{bB}}$ & $3,50^{\mathrm{bB}}$ \\
\hline
\end{tabular}

Cor vermelha; odor característico; sabor característico $(1=$ pouco; $10=$ muito); consistência do gel $(1=$ duro; $10=$ mole). Médias seguidas de mesma letra minúscula na linha e maiúscula na coluna não diferem entre si, pelo Teste de Tukey $(\mathrm{p}<0,05)$. 
Tabela 6. Valores médios para os atributos sensoriais, brilho e sabor doce das amostras de geleiada de morango.

\begin{tabular}{ccc}
\hline Variável & Brilho & Sabor doce \\
\hline Temperatura $\left({ }^{\circ} \mathrm{C}\right)$ & & \\
\hline 20 & $9,20^{\mathrm{a}}$ & $8,87^{\mathrm{a}}$ \\
30 & $9,00^{\mathrm{a}}$ & $8,47^{\mathrm{a}}$ \\
40 & $8,80^{\mathrm{a}}$ & $8,83^{\mathrm{a}}$ \\
Dias & & \\
0 & $10,00^{\mathrm{a}}$ & $9,67^{\mathrm{a}}$ \\
30 & $8,00^{\mathrm{c}}$ & $7,78^{\mathrm{b}}$ \\
60 & $9,11^{\mathrm{b}}$ & $8,61^{\mathrm{b}}$ \\
90 & $8,78^{\mathrm{bc}}$ & $8,72^{\mathrm{ab}}$ \\
180 & $9,11^{\mathrm{b}}$ & $8,67^{\mathrm{ab}}$ \\
$\mathrm{CV}(\%)$ & 7,22 & 12,70 \\
\hline
\end{tabular}

Brilho; sabor doce $(1=$ pouco; $10=$ muito $)$. Médias seguidas de pelo menos uma letra comum, nas colunas, não diferem significativamente entre si, pelo teste de Tukey $(\mathrm{p}<0,05)$

\section{Conclusões}

As geleiadas apresentaram qualidade adequada com relação ao teor de ácido ascórbico na ocasião do processamento, porém apresentaram baixa taxa de retenção de vitamina $\mathrm{C}$, tendo, aos 60 dias, seu conteúdo reduzido em mais de $98 \%$, independentemente da condição de armazenamento.

O teor de umidade do produto foi inversamente proporcional ao aumento de temperatura de armazenamento.

$\mathrm{O}$ produto armazenado às temperaturas de 20 e de $30^{\circ} \mathrm{C}$ não apresentaram alterações pronunciadas na coloração, odor, sabor e textura. A temperatura de $40^{\circ} \mathrm{C}$ afetou negativamente, provocando o escurecimento e perdas de odor, sabor e textura.

\section{Referências bibliográficas}

ASSOCIAÇÃO BRASILEIRA DE NORMAS TÉCNICAS - ABNT. NBR 12994. Métodos de análise sensorial dos alimentos e bebidas. São Paulo, 1993. 2 p.

Association of Analytical Chemists International - AOAC. Official methods of analysis of the Association of Analytical Chemists International. 14 ed. Washington, 1992.
FREEDMAN, L.; FRANCIS, F. J. Effect of ascorbic acid on color of jellies. Journal of Food Science, n. 49, p. 1212-1213, 1984.

GAVA, A. J. Princípios de tecnologia de alimentos. São Paulo: Nobel, 1984.

GOMES, F. P. Curso de estatística experimental. 10 ed. São Paulo: Nobel, 1982.

INSTITUTO ADOLFO LUTZ. Métodos químicos e físicos para análises de alimentos. 3 ed. São Paulo: IAL, v. 1, n. 4.5, 1985a.

INSTITUTO ADOLFO LUTZ. Métodos químicos e físicos para análises de alimentos. 3 ed. São Paulo: IAL, v. 1, n. 4.7.2, 1985b.

INTERNATIONAL ORGANIZATION FOR STANDARDIZATION ISO. ISO 5497: Sensory Analysis-Methodology-Guidelines for the preparation of samples for which direct sensory analysis is not feasible. Genève, 1982. $4 \mathrm{p}$.

INTERNATIONAL ORGANIZATION FOR STANDARDIZATION ISO. ISO 4121: Sensory Analysis-Methodology-Evaluation of food products by methods using scales. Genève, 1987. 8 p.

INTERNATIONAL ORGANIZATION FOR STANDARDIZATION ISO. ISO 8589: Sensory Analysis-General guidance for the design of test rooms. Genève, 1988. 9 p.

LABORATORY Techniques in Food Analysis. London: Butterworths, 1973.

LOZANO, J. E.; IBARZ, A. Colour changes in concentrated fruit pulp during heating at high temperatures. Journal of Food Engineering, v. 31, n. 3, p. 365-373, 1997.

MOURA, S. C. S. R. et al. Cinética de degradação de polpas de morango. Brazilian Journal of Food Technology, v. 4, n. 1, p. 115-121, 2001.

SKREDE, G. et al. Color stability of strawberry and blackcurrant syrups. Journal of Food Science, v. 57, n. 1, p. 172-177, 1992.

STROHECKER, R.; HENNING, H. M. Analisis de vitaminas: métodos comprobados. Madrid: Paz Montalvo, 1967.

TEIXEIRA NETO, R. O.; VITALI, A. A. Reações de transformação e vida-de-prateleira de alimentos processados. 3 ed. Campinas: Ital, 2004.

VENDRUSCOLO, J. L. S.; VENDRUSCOLO, C. T. Sistema de produção do morango. Disponível em: <http://sistemasdeproducao.cnptia. embrapa.br/FontesHTML/Morango/SistemaProducaoMorango/ cap14.htm>. Acesso em: 15 Maio 2007. 